\title{
RELAÇÕES ENTRE ADULTO E CRIANÇA NOS RELATÓRIOS DE ESTÁGIO NA EDUCAÇÃO INFANTIL
}

\author{
RELATIONS BETWEEN ADULT AND CHILD IN STAGE REPORTS IN CHILD EDUCATION
}

\author{
Bárbara Fagundes de Lima ${ }^{1}$ \\ Christian Muleka Mwewa ${ }^{2}$
}

\section{http://dx.doi.org/10.52641/cadcaj.v6i4.524}

\begin{abstract}
RESUMO: Os novos Estudos da Criança trazem o reconhecimento da incompletude e do caráter fragmentário das abordagens que tradicionalmente assumiam a criança como objeto de conhecimento, críticas à visão teleológica, lineares e socialmente vazias do desenvolvimento infantil. Por meio da abordagem qualitativa e quantitativa, nos apropriamos do instrumental de análise de documento para verificar a relação entre adulto e criança presente nos relatórios de estágio na Educação Infantil do curso de Pedagogia da Universidade Federal de Mato Grosso do Sul - Campus de Três Lagoas (UFMS/CPTL). Dentre os principais referenciais teóricos, tomamos como base os estudos na área da Sociologia da Infância. Concluímos que a relação entre adulto e criança depende da concepção do adulto sobre o entendimento da criança como sujeito e da infância como etapa geracional, não necessariamente presa ao espaço e a um tempo, uma vez que ser criança ou estar na infância é uma construção histórica e cultural, ou seja, um permanente devir.
\end{abstract}

Palavras-chave: Educação Infantil; Relatórios de estágio; UFMS/CPTL; Relação adulto e criança.

Abstract: The new Child Studies bring the recognition of the incompleteness and fragmentary nature of the approaches that traditionally assumed the child as an object of knowledge, critical to teleological vision, linear and socially empty of child development. Through the qualitative and quantitative approach, we use the document analysis tool to verify the relationship between adult and child present in the reports of Internship in Child Education of the Pedagogy course of the Federal University of Mato Grosso do Sul Campus of Três Lagoas (UFMS/CPTL). Among the main theoretical reference, we adopt the studies in the area of Sociology of Childhood. We conclude that the relationship between adult and child depends on the adult's conception about the child's understanding as a subject and childhood as a generational step, not necessarily bound to space and at one time since being a child or being in childhood is a historical construction and cultural, that is, a permanent becoming.

Key-works: Child education; Stage Reports; UFMS/CPTL; Adult and child relationship.

\section{INTRODUÇÃO}

Diante do nosso objetivo principal, esperamos oferecer algumas ferramentas para pensar o desenvolvimento das sociedades em que estamos inseridos. Para o estudo dos fenômenos que

\footnotetext{
${ }^{1}$ Mestranda no Programa de Pós-Graduação em Educação (PPGEdu/CPTL) da Universidade Federal de Mato Grosso do Sul (Campus Três Lagoas/CPTL). Formada em Pedagogia na mesma universidade. E-mail: barbarafagundeslima@gmail.com.

${ }^{2}$ Doutor em Ciências da Educação pela Universidade Federal de Santa Catarina (com estágio doutoral na Université Paris 1 - Panthéon Sorbonne). Professor e coordenador do Programa de Pós-Graduação em Educação (Campus Três Lagoas/CPTL); Professor do Programa de Pós-Graduação em Educação (Campus Campo Grande), ambos da Universidade Federal de Mato Grosso do Sul. E-mail: christian.mwewa@ufms.br. Endereço Postal: Universidade Federal de Mato Grosso do Sul, Brasil; Av. Ranulpho Marques Leal, 3484, Três Lagoas/MS - 79613-000 UFMS/CPTL/Unidade II/Bloco III, Três Lagoas, MS - Brasil.
} 
circundam a educação os métodos são variados, porém, nos pautamos na pesquisa qualitativa, pois, "o termo qualitativo implica uma partilha densa com pessoas, fatos, locais que constituem objetos de pesquisa, para extrair desse convívio os significados visíveis e latentes que somente são perceptíveis a uma atenção sensível.” (CHIZZOTTI, 2006, p. 28).

Portanto, elegemos a abordagem qualitativa, uma vez que esta se baseia em uma perspectiva que idealiza o conhecimento como um modo socialmente construído pelos sujeitos nas suas relações cotidianas, enquanto influenciam a realidade, transformando-a e sendo por ela transformados. Segundo André (2013, p. 96), “[...] o mundo do sujeito, os significados que atribui às suas experiências cotidianas, sua linguagem, suas produções culturais e suas formas de interações sociais constituem os núcleos centrais de preocupação dos pesquisadores." Logo, continua a autora, "[...] se a visão de realidade é construída pelos sujeitos, nas interações sociais vivenciadas em seu ambiente de trabalho, de lazer, na família, torna-se fundamental uma aproximação do pesquisador a essas situações.” (ANDRÉ, 2013, p. 96).

Por meio da abordagem qualitativa e quantitativa, nos apropriamos do instrumental de análise de documento para observar a relação entre adulto e criança presente nos relatórios de estágio na Educação Infantil do curso de Pedagogia da Universidade Federal de Mato Grosso do Sul - Campus de Três Lagoas (UFMS/CPTL). Dentre os principais referenciais teóricos, tomamos como base os estudos na área da Sociologia da Infância.

Inicialmente, optamos por quantificar os relatórios de estágio produzidos entre os anos de 2012 e 2014, pois, nesse período, tínhamos uma relação mais próxima com os acadêmicos e presenciamos algumas inquietações relacionadas às formas de relação entre adultos e crianças na Educação Infantil. Foram quantificados 28 relatórios de estágio do período considerado, dos quais 12 foram realizados em duplas e 16 produzidos individualmente. Dos 16 Centros de Educação Infantil (CEI) existentes no município de Três Lagoas, pelo menos 10 foram contemplados nos relatórios, e um dos documentos apresenta os dados de um CEI localizado na cidade de Mirandópolis, no estado de São Paulo.

Após uma análise prévia, observamos que os dados desses 28 relatórios seriam muito abrangentes, do ponto de vista da sua extensão, para serem analisados neste artigo. Restringimonos, portanto, a seis relatórios e definimos alguns critérios para aproximá-los do nosso objetivo. Assim, os relatórios foram escolhidos de acordo com os seguintes critérios: terem sido produzidos entre os anos de 2012 e 2014, por se tratar de estágios na mesma etapa de ensino (Educação Infantil I, 0 a 3 anos), elaborados individualmente, orientados pela mesma professora, e, o fator mais decisivo da nossa escolha, os que identificamos de forma mais clara a relação adulto e criança, e com uma certa frequência. 
Nesse momento de coleta de dados, pudemos observar que os relatórios, em sua maioria, para a execução do estágio, seguiram um padrão dividido em três fases: a primeira, a da "Observação", quando os(as) estagiários(as) conheciam a estrutura física do CEI, a estrutura organizacional e a estrutura documental; a segunda, a da "Participação", quando os(as) estagiários(as) já tinham contato direto com o(a) professor(a) e com as crianças exercendo uma função de auxiliar do profissional da educação, participando ativamente da rotina diária, com o intuito de vivenciar a prática docente; e, por último, a fase da "Regência", momento no qual os(as) estagiários(as) produziam um plano de aula e o executavam sob a supervisão do professor regente da sala em que realizaram o estágio.

Contudo, em se tratando da estrutura física do relatório, identificamos uma falta de estrutura-padrão para a sua produção. Esse fato dificultou a nossa coleta de dados, pois, por se tratar de um documento científico no qual foram registrados detalhes dos resultados de uma experiência, sendo gerados possíveis dados para posteriores pesquisas, como é caso deste estudo, verifica-se a necessidade de uma padronização da estrutura para a validação da cientificidade do material.

A questão da postura ética na escrita e na execução do estágio não esteve presente nos relatórios. Porém, em conversas informais com os acadêmicos que realizaram o estágio no ano supracitado, tivemos o relato de que no Termo de Compromisso de Estágio não consta nenhum artigo direcionado às questões éticas. As orientações relacionadas ao comportamento ético no decorrer do estágio são feitas no primeiro dia de aula com a turma, pela professora da disciplina, e se resumem em: vestimentas adequadas; apresentação diária à direção do CEI, antes de entrar na sala de aula; se forem identificadas ações criminais, deve-se reportar, primeiramente, à supervisão da UFMS, para que as ações sejam feitas pela instituição e nunca pelo estagiário, resguardando-o; que todos os relatos realizados ao final da disciplina, na apresentação final do estágio, devem se restringir à turma, de forma a garantir sigilo desses relatos, e que as fotos tiradas durante o estágio devem ter o rosto das crianças tapado ou borrado, devido à autorização do uso de imagem e garantia do sigilo supracitado.

A preocupação com a qualidade dos dados deste trabalho nos fez ter uma postura muito cautelosa para garantir tanto a cientificidade quanto a ética neste artigo, nos restringindo a escolhas de relatórios que nos proporcionassem dados relacionados diretamente com o nosso objetivo, para que o tempo e a praticidade fossem nossos aliados no alcance da concepção do adulto sobre o entendimento da criança, como sujeito, e da infância.

Manuel Sarmento (2013) ressalta que a Sociologia da Infância é uma disciplina científica, filiada à Sociologia, que objetiva conhecer a infância como categoria social e as crianças como 
membros da sociedade, atores sociais e agentes de cultura. Algumas observações em literatura em Sociologia da Infância procuram estabelecer a distinção entre diferentes abordagens, a partir da tradição das escolas de pensamento sociológico enraizadas em distintos países, regiões do mundo ou universos linguísticos (BUHLER-NIEDERBERGER, 2010; MONTANDON, 1998; SIROTA, 1998, 2012 apud SARMENTO, 2013).

O artigo está dividido em quatro partes: esta introdução (1) na qual localizamos o tema e as subsequentes subdivisões do artigo; o desenvolvimento (2), por sua vez subdividido em "Documentos de cultura: relatórios de estágio na Educação Infantill, em que são apresentados os conteúdos dos relatórios com ênfase na sua importância como documentos que registram e retratam certa história da infância, e "Relação entre adulto e criança nos contextos dos CEIs em Três Lagoas: uma análise a partir dos documentos de cultura", em que se busca enfatizar a análise da relação adulto/criança retratada nos relatórios por meio das instâncias do cuidado, do espaço físico e da afetividade; as considerações finais (3), nas quais retomamos o percurso da pesquisa e apresentamos as nossas avaliações dos estudos em tela; e, finalmente, as referências (4) que serviram como base teórica para este artigo.

O entendimento da criança como uma fase geracional em que é preciso mais do que cuidado, mas uma fase que deve ser humanizada num processo permanente de oportunizar autonomia geracional, uma vez que essas crianças devem ser protegidas e orientadas a como agir no mundo sem autoritarismo, mas com autoridade (ARENDT, 2002). Urge efetivar os direitos da criança na sua inteireza nos contextos educativos de Três Lagoas (MS).

\section{DESENVOLVIMENTO}

\subsection{Documentos de cultura: relatórios de estágio na Educação Infantil}

Apresentamos as concepções de infância e criança para entendermos as abordagens construídas sobre as relações intergeracionais (adulto e criança) contidas nos relatórios de estágio da Educação Infantil I (0 a 3 anos) do curso de Pedagogia, do período de 2012 a 2014, no Campus de Três Lagoas da Universidade Federal de Mato Grosso do Sul (UFMS).

Entendemos que a concepção de infância foi construída historicamente ao longo dos anos, passando por diferentes mudanças, para chegarmos hoje às visões que temos de criança. Dessa forma, para entendermos o conceito de infância e de criança, faremos uma pequena contextualização histórica, pois sabemos que a criança nem sempre foi vista pela sociedade como um sujeito que precisa de cuidados especiais.

O historiador francês Philipe Ariès (1981) defende a inexistência de tal sentimento durante a Idade Média e apresenta, de acordo com suas análises, algumas justificativas para tal ideia, realizando um completo e denso estudo sobre a iconografia e os documentos da época. 
É preciso compreender, porém, que para o autor "falta de sentimento de infância" é a ausência de consciência a respeito da particularidade infantil, falta de conhecimento sobre as individualidades que distinguem as crianças de adultos, resultando, assim, em uma incompreensão de que havia uma dependência não somente física, mas também emocional por parte das crianças.

Conforme o padrão de comportamento, os sentimentos de vergonha e medo foram se modificando, passando a fazer parte do indivíduo, e a dificuldade de falar com as crianças sobre esses assuntos também cresceu. Entretanto, essa dificuldade não foi guiada por motivos racionais, mas sim por proibições sociais e resistências que se impuseram por parte dos próprios adultos. Seu próprio superego os fez guardar silêncio. É a estrutura da personalidade dos adultos que torna difícil falar sobre algo que lhes parece, agora, secreto.

A primeira impressão de que não havia lugar para a infância na Idade Média deve ser atenuada com a compreensão de que o sentimento dos indivíduos e a percepção da própria sociedade sobre si mesma e suas crianças eram completamente diferentes do que conhecemos hoje. Aos poucos, esse sentimento foi se tornando mais forte nos indivíduos, e eles puderam perceber a primeira infância como um período importante e único da vida que deve ser cercado de cuidados e proteção.

Para pensarmos essas questões em relação à criança brasileira, é necessário procurarmos nossas próprias respostas, pois a realidade no Brasil foi muito diferente da apresentada nos países europeus, e um dos problemas a ser considerado é que, entre nós, a escolarização e a emergência da vida privada chegaram com grande atraso se comparado ao que aconteceu em outros países ocidentais. Devemos inclusive acrescentar a nossa análise os problemas referentes à colonização, bem como os que vieram como herança dos colonizadores.

No Brasil, do período colonial até meados do século XIX, temos o que Marcílio (1998) chama de fase caritativa, na qual surgem as primeiras instituições de proteção à criança órfã ou abandonada, as primeiras rodas de expostos, e, com elas, as instituições de atendimento às crianças, as misericórdias. $\mathrm{O}$ assistencialismo da fase caritativa tem como característica principal o sentimento de fraternidade, de conteúdo paternalista sem pretensão de mudanças sociais.

Cabe salientar que as casas da roda não eram asilos. As crianças ali deixadas, num primeiro momento, eram cuidadas por amas de leite, que amamentavam os bebês em troca de pagamento, e, em seguida, essas crianças eram enviadas a famílias que recebiam ajuda financeira para cuidar delas. Porém, de acordo com Marcílio (1998, p. 237), a maioria das crianças abrigadas nas rodas falecia antes de completar um ano e "[...] de todas as categorias que formaram a população brasileira, incluindo os escravos, a dos expostos foi a que apresentou os maiores índices de mortalidade infantil, até o fim do século XIX." 
Pode-se dizer que as creches e os jardins de infância, assim como outras instituições, constituíram um "[...] conjunto de instituições modelares de uma sociedade civiliz̧ada, propagadas a partir dos países europeus centrais, durante a Era dos Impérios, na passagem do século XIX ao XX.” (HOBSBAWN, 1988 apud KUHLMAN JR., 2000, p. 8). A creche é criada na França em 1844 e se estabelece como instituição nacional e internacional a partir de 1870. No Brasil, ainda no império, surge primeiro como ideia, para no período da República efetivar-se em instituições espalhadas pelas principais cidades, chegando a 15 creches em 1921 e 47 em 1924 (KUHLMAN JR., 2000).

Ao contrário do que aconteceu na Europa, no Brasil até o século XIX, praticamente não existiam instituições destinadas à educação da criança. Como vivíamos num meio $[\ldots]$

Roda dos Expostos marca a história das instituições de assistência a infância. Tal roda surgiu no período Colonial, pela Santa Casa de Misericórdia, em Salvador logo após no Rio de Janeiro, durando em alguns cantos até a República. Nesse espaço atendia-se a bebês abandonados pelas mães solteiras que buscavam esconder a desonra de esperar um filho ilegítimo, ou famílias de condições precárias. No Brasil, em 1862, encontramse relatos das rodas dos expostos na Santa Casa de Misericórdia de Salvador, assistindo à infância nas instituições de caráter assistenciais.

$[\ldots]$

Após a abolição da escravatura cresce a migração para a zona urbana, este movimento gera condições para o surgimento das grandes cidades e posteriormente $o$ desenvolvimento da cultura e tecnologia. Contudo, ao abolir os escravos novos problemas são gerados para a sociedade, pois o que aconteceria com os filhos da escravidão? Não existiam espaços reservados para o cuidado dessas crianças e os pais não tinham condições de educá-los, assim, muitas dessas crianças eram abandonadas. Não podemos deixar de falar da forte influência da proclamação da República para a elaboração de iniciativas destinadas a proteção à infância. Neste período são criadas entidades de amparo à criança, ou seja, as creches, asilos e internatos, objetivando o combate ao alto índice de mortalidade infantil e assegurar o cuidado das crianças pobres. (MENDES, 2015, p. 96-97).

As primeiras instituições, tanto na Europa quanto nos Estados Unidos, tinham o objetivo de cuidar e proteger crianças para que as mães pudessem trabalhar, e cujo enfoque, nesse primeiro momento, foi o de cuidar, guardar, proporcionar higiene, alimentação e cuidados físicos. Apesar disso, se preocuparam também com as questões de educação, uma vez que se apresentaram como pedagógicas já em seu início (KUHLMAN JR., 2000; PASCHOAL; MACHADO, 2009).

No Brasil, o processo de industrialização e de entrada da mulher no mercado de trabalho trouxe a necessidade de instituições que atendessem às crianças. As instituições que tiveram seu início como concessão dos proprietários das fábricas passaram a ter outro enfoque, sendo reivindicadas como um direito de todas as mulheres trabalhadoras, baseando-se no movimento da teoria da privação cultural e de uma educação compensatória. De acordo com Kramer (1995), a abordagem da privação cultural está apoiada no entendimento de que as crianças das classes populares fracassam porque apresentam "desvantagens socioculturais", ou melhor, carências de 
ordem social. Essas desvantagens são defasagens tanto de ordem intelectual quanto linguística, ou até mesmo afetiva.

Nesse sentido, as crianças apresentam "insuficiências" que diziam ser necessário compensar através de métodos pedagógicos adequados, para diminuir a diferença entre essas crianças "desfavoráveis" e as demais, na área do desempenho escolar. Com isso, pretendia-se reduzir ou eliminar as desvantagens educacionais visando o que se chamava de intervenção precoce. Não é realizada uma definição objetiva do que se pretendia dizer com "desvantagem cultural” (ou carência). Kramer (1995, p. 33) nos mostra que “[...] ela é entendida enquanto um atraso intelectual ou uma distorção emocional provocados por um ambiente fraco em estimulação.”

A abordagem da privação cultural desconsiderou as relações existentes entre a instituição escolar e as classes sociais. A escola foi considerada como "neutra ou apolítica", sendo vista como o meio para superação de diferenças provenientes da origem de classe social por meio da educação compensatória. A pedagogia da compensação desenvolvida nas escolas de atendimento à primeira infância supôs um "modelo único de criança", um "modelo científico de criança", e, a partir daí, o filho do operário foi considerado como uma criança burguesa incompleta. Nesse sentido, a criança contida no modelo único e científico teria a possibilidade de aprender, e, por outro lado, a criança "carente" não. O conhecimento é reduzido a um processo puramente psicológico, em vez de ser compreendido como resultante da prática social (KRAMER, 1995).

Com o passar do tempo, a nomenclatura utilizada deixa de considerar a escola maternal como a dos pobres, em oposição ao jardim de infância da elite, e passa a defini-la como a instituição que atenderia à faixa etária dos 2 aos 4 anos, enquanto que o jardim seria para as crianças de 5 a 6 anos. Mais tarde, essa especialização etária passou a fazer parte dos nomes das turmas em instituições de atendimento à primeira infância.

Durante todo o período do regime militar, o atendimento à infância foi considerado de menor importância, e as verbas destinadas a essa faixa etária foram as mais insignificantes, mas, por outro lado, se imaginava que os programas voltados para a infância pudessem ser a solução dos problemas sociais. Com poucos investimentos, porém, pouco foi feito. Somente com o processo de redemocratização política e a promulgação de uma nova Constituição Federal, outros olhares foram lançados sobre as escolas de educação para a infância. A Constituição Federal de 1988 deu origem a uma nova Lei de Diretrizes e Bases, a Lei no 9.394 (BRASIL, 1996) e, com ela, a ideia de que as instituições de atendimento à primeira infância não estariam preocupadas apenas com o cuidado, mas também e principalmente com a educação. 
Assim, na segunda metade da década de 1980 as crianças passaram a ser reconhecidas como sujeitos de direitos. A Constituição Federal de 1988 descreve pela primeira vez a Educação Infantil como etapa designada ao atendimento promovido em creches e pré-escolas às crianças de 0 a 6 anos, sendo reconhecida como dever do Estado (BRASIL, 1988). A Educação Infantil deixa de estar relacionada à assistência social para tomar seu lugar como primeira etapa da Educação Básica. Esse direito foi corroborado pela Lei de Diretrizes e Bases da Educação Nacional, Lei $n^{\circ} 9.493 / 1996$.

\subsection{Relação entre adulto e criança nos contextos dos CEIs em Três Lagoas: uma análise a partir dos documentos de cultura}

Neste item, analisaremos como são retratadas as relações entre adulto e criança nos relatórios analisados. Depois da análise dos relatórios em consonância com o nosso objetivo, chegamos a três categorias, descritas a seguir, escolhidas por sua recorrência nos relatórios analisados.

A primeira categoria, que chamamos de cuidar, temos como sujeitos os adultos e como estes se relacionam com as crianças nos momentos de higiene, cuidado e necessidades fisiológicas. Por outro lado, chamamos a atenção para não localizar as ações de cuidado apenas no corpo biológico, pois elas transcendem essa dimensão. Nessa categoria aparecem questões como o momento certo de ir ao banheiro, beber água e como o professor acompanha e entende esses momentos de cuidados. A segunda categoria, espaço físico, é exclusiva para as questões relacionadas com espaços de convivência entre crianças e adultos, tais como área verde, quadra, parque e espaços nas salas de aula. Nessa categoria, procuramos destacar e entender como os gestores, diretores(as), veem esses espaços. A terceira categoria é a afetividade, na qual buscamos identificar como acontecem as relações de afetividade entre adultos e crianças, como as instituições como um todo se relacionam afetivamente com as crianças, visto que a afetividade é algo presente na vida da criança a todo o momento. Apresentamos a seguir a análise das três categorias.

$\mathrm{Na}$ análise da primeira categoria, cuidar, nos interessa saber qual a percepção dos adultos (educadores) a respeito do cuidar e como ocorre a relação adulto e criança nesse momento. Os relatórios indicam as necessidades fisiológicas como referentes ao cuidar do próprio corpo além do registro da saúde bucal. Nessa direção, Richter (2005, p. 84, grifos da autora) afirma que: “A higiene se destaca como ciência da infância e se fortalece quando dirigida às famílias por meio de artigos e catálogos e às instituições educacionais através de manuais e outros recursos 
materialmente estruturados.” Encontramos os seguintes trechos nos relatórios referentes a essa questão:

Considerei interessante a atividade em que tive oportunidade de participar, onde as crianças aprendiam, na prática, sobre a bigiene bucal.; As crianças são ensinadas a cuidar do próprio corpo, mas não com autonomia já que a auxiliar da professora chamava as meninas, uma de cada vezpara arrumar os cabelos com rabo de cavalo.

Quanto às necessidades fisiológicas as crianças nem sempre são atendidas de imediato com aceitação e acolhimento, pois muitos dizem que estão com sede e tem que aguardar a hora certa para beber água. Ou muitas vezes querem ir ao banheiro e a professora não deixa por achar que não devem ir naquele momento.

No primeiro trecho, o cuidar está associado com o educar, mediado por uma atividade prática. Tal associação se deve ao fato de que, ao mesmo tempo em que a professora cuida da higiene bucal, ela ensina a criança a fazer sozinha e, dentro desse processo, podemos identificar o desenvolvimento da autonomia, da coordenação motora, entre outros, formando a criança em sua integralidade. $\mathrm{O}$ adulto reconhece a criança como um sujeito de direitos que necessita de cuidados, mas também de educação. Dessa forma, Sarmento (2013) esclarece que os Estudos da Criança procuram compreender a criança como ser biopsicossocial, e a infância como categoria estrutural da sociedade, procurando realizar tais estudos numa perspectiva totalizante, e, por consequência, interdisciplinar.

No trecho seguinte, vemos que há um cuidar, porém sem autonomia da criança nesse exercício. Percebe-se uma relação em que o profissional não reconhece a criança com um ser capaz de exercer suas necessidades básicas sozinhas. A Sociologia da Infância classifica essa visão como abordagens tradicionais em que as crianças são vistas socialmente como vazias de capacidade/competência de ação. Portanto, no cuidado, permanece a tutela do adulto sobre a criança. Esse procedimento amplamente criticado no contexto dos escritos que tematizam a Educação Infantil vai de encontro ao que preconiza, em especial, a Sociologia da Infância, que admite tacitamente que a criança é um ser ativo e de direito. Na permanente tutela dos adultos, a criança vê os seus direitos tolhidos e as possibilidades da sua autonomia cerceadas. Por outro lado, pode-se dizer que quanto mais direitos são dados às crianças mais se legitima a tutela dos adultos sobre elas, pois não são as crianças que elaboram as leis e muito menos que participam da sua elaboração. Portanto, os direitos das crianças só serão direitos delas quando elas puderem 
participar da elaboração das leis que lhes delegam direitos. Essa afirmação não pode ser confundida com a perspectiva que reduz as crianças a cidadãos do futuro, negando-as a ação no presente. Reafirmamos que se faz imprescindível oportunizar a inclusão das perspectivas infantis na elaboração dos direitos a elas concedidos. Para tanto, deve-se buscar ou criar mecanismos/estratégias, ou tecnologias sociais, para a materialização dos anseios das crianças, tomando-as como autoras das suas possibilidades de ação histórica e social. Do contrário, permanecemos na tentativa de dizer como o outro deve ser tratado. E, no último trecho, temos uma relação de autoridade (não confundir com autoritarismo), que negligencia as necessidades básicas da criança. Já que no espaço educativo o adulto é responsável por proteger as crianças, a negligência desse dever configura-se em barbárie. Ao contrário de outros mamíferos, o ser humano, depois do seu nascimento, precisa por mais tempo da proteção direta de outro ser humano mais experimentado no mundo.

As discussões apresentadas aqui nos mostram que quando o profissional entende a criança como um ser de direitos, membro da sociedade, ator social e agente de cultura, reconhece a infância como categoria social. Esse reconhecimento poderá proporcionar uma relação saudável para com a criança. Contrapondo essa teoria, vemos, no último trecho apresentado dessa categoria, uma relação adulto e criança de autoridade na qual só o adulto é redentor do conhecimento, silenciando a criança em suas necessidades mais básicas, como beber água e ir ao banheiro. Nesse sentido, concordamos com Richter (2005) que, ao analisar o cotidiano da rotina de uma creche na cidade de Florianópolis (SC), afirma que:

\begin{abstract}
Ao tratarmos da educação do corpo nos momentos de higiene, buscamos tecer algumas considerações acerca da formação dos espaços urbanos como cenários para o empreendimento de políticas e discursos higienistas em prol da assepsia dos ambientes e das condutas humanas, com especial atenção às crianças e às instituições de atendimento à infância, alvos de investimento de uma racionalidade que pretende organizar a sociedade. (RICHTER, 2005, p. 83).
\end{abstract}

$\mathrm{Na}$ categoria espaço físico, procuramos identificar como os espaços do CEIs refletem a relação adulto e criança, visto que essa categoria (espaço) não é uma preocupação somente do educador, mas também das autoridades municipais. Em todos os relatórios analisados encontramos relatos referentes ao espaço físico, por se tratar de um item obrigatório nos documentos. Durante nossa análise observamos um grande contraste entre os espaços físicos, uma vez que, enquanto alguns CEIs têm salas espaçosas, parques e refeitórios, outros sofrem até com a falta de água, pois não têm caixa d'água. No entanto, buscamos destacar a falta de área coberta e parque, visto que esses itens se repetem com mais frequência nos relatórios.

Segundo Richter (2005, p. 133), "no mundo contemporâneo os locais destinados para tal são vistos como espaços em que se podem fixar 'recursos' destinados à ocupação do 'tempo livre' das crianças. 
De acordo com os relatórios:

Não há local adequado para recreação, a ausência de um parquinho ou pátio dificulta o desenvolvimento de atividades recreativas, pois a grade curricular contempla a Educação Física, entretanto, não há espaço físico adequado.

Não bá refeitório na escola, as crianças maiores são alimentadas em algumas mesas no pátio, e as menores dentro da sala de aula.

$\mathrm{Na}$ área do fundo é onde se encontra o espaço de laz̧er das crianças e onde se desenvolvem atividades ao ar livre e aulas de educação física. [...] tem a oportunidade diária de frequentar e explorá-lo. É importante destacar que, neste quintal, existe um espaço muito grande que fica exposto ao sol, com poucas árvores ou plantas.

Segundo as Diretrizes Curriculares Nacionais para a Educação Infantil (BRASIL, 1998), é dever do Estado garantir a oferta da Educação Infantil pública, gratuita e de qualidade, sem requisitos de seleção. Dessa forma, questionamos: qual a qualidade de ensino ofertada nesses estabelecimentos, como são vistas as crianças e qual a relação adulto e criança que se estabelece?

Esse mesmo documento norteador que regulamenta a educação nos CEIs afirma que, para que ocorra o desenvolvimento integral das crianças, é importante que se assegurem os deslocamentos e os movimentos amplos das crianças nos espaços internos e externos às salas de referência das turmas e à instituição (BRASIL, 1998).

Retomando a pesquisa de Richter (2005), a autora indica em uma de suas observações que:

Os momentos do parque são vistos pelas professoras como um período em que as crianças "se soltam" [...], em que "elas ficam mais livres" [...]. Em entrevista, são unânimes ao afirmar que o parque é um "espaço mais livre" e que seu trabalho consiste em "observar sem mediar muito", [...] "observar eles brincarem" [...]. Ou, ainda: "O momento é mais de observar" [...]. E observar, segundo revelam, implica em: "Atender" $[\ldots]$, "ajudar" [...], "resolver conflitos" [...]. (RICHTER, 2005, p. 131).

Nesse sentido, analisamos que, mesmo que não existam espaços adequados nas instituições de ensino, a postura do educador em relação à criança não deve ser de indiferença em relação à necessidade da criança de se movimentar. Portanto, o educador deve criar mecanismos que possam oportunizar essa experiência no contexto educativo. No primeiro trecho analisado, os estudantes alegam que a falta de espaço dificulta a realização das atividades externas, mas não afirmam que não há. No segundo trecho, mesmo sem um espaço adequado para as refeições, os profissionais procuram alternativas, para que esse momento tão importante para o desenvolvimento da criança ocorra da melhor forma possível. Isso nos mostra uma preocupação 
que esses profissionais têm com a qualidade da relação adulto e criança no que diz respeito a proporcionar melhores condições para o pleno desenvolvimento da criança, como propõe Valadão (1998 apud RICHTER, 2005). Existe uma relação adulto e criança que reconhece os direitos desses indivíduos, mas será que as autoridades também reconhecem? Por que temos umas instituições com tantos recursos e outras com tão pouco? Quais os critérios de escolha de prioridades? Considerando-se que umas têm estruturas que atendem aos dispositivos legais e outras não, mas todas atendem crianças de 0 a 3, e algumas atendem de 0 a 6 anos.

$\mathrm{Na}$ categoria afetividade, procuramos identificar nos relatórios como os adultos se relacionam com as crianças afetivamente. Dos seis relatórios analisados, encontramos em apenas dois a descrição dessa relação de afetividade. Independentemente da classe social, da idade, do gênero ou da sua origem, a afetividade está constantemente presente na vida da criança e nas suas relações com os adultos.

As questões de afetividade são bem recebidas e tem bastante afeto e atenção dos profissionais.

A professora responsável pelo berçário no qual desenvolvi meu projeto é muito atenciosa e cuidadosa com os bebês.

A relação entre professores, atendentes e crianças é bastante saudável, é importante ressaltar que a maior parte do dia essas crianças passam com esses profissionais então acaba se criando um vínculo afetivo, uma relação de confiança entre ambos.

Os relatórios destacam que as questões de afetividade não se trata de algo que seja prioritário nas observações realizadas nos estágios, pois os adultos se esquecem, por parte dos adultos de associar o cuidar e o educar na Educação Infantil. Assim, a instituição de ensino (contexto educativo) tem o papel de promover o desenvolvimento integral das crianças em seus aspectos físicos, emocionais, cognitivos, entre outros. O desenvolvimento emocional das crianças é uma questão importantíssima para que elas consigam lidar com as emoções pelas quais passam em seu dia a dia. Por exemplo, é tão legítimo o sofrimento de uma criança diante da perda de alguém importante, de uma decepção amorosa ou relacional, visto que o afeto é um sentimento que nem todas as crianças têm em seus lares, isto é, em suas famílias ou entre seus pares.

\section{Considerações finais}

$\mathrm{Na}$ relação adulto e criança é preciso considerar as formas como as crianças elaboram o seu desenvolvimento para se moverem no mundo sem a excessiva tutela dos adultos. As Diretrizes Curriculares para a Educação Infantil é um documento que orienta como as práticas e 
as crianças devem ser vistas pelas pessoas que as atendem. Dessa forma, concluímos que o referido documento possibilita uma aprendizagem de qualidade e com significado, respeitando as crianças e suas relações com outras crianças e entre os adultos.

Os relatórios analisados, por sua vez, apresentam uma estrutura-padrão devido às orientações do curso de Pedagogia, porém, as observações aconteceram aleatoriamente seguindo cada autor(a) do relatório, mas atendendo as orientações do curso. Nos relatórios não existe um objetivo a ser observado, e essa não linearidade dificultou o acompanhamento e a apresentação dos dados neles contidos. Portanto, é possível afirmar que a relação adulto e criança não apareceu de forma clara, a não ser pelas ações identificadas e elencadas nas categorias cuidar, espaço físico e afetividade. É importante que seja discutido nas disciplinas de estágio, por exemplo, o tema aqui proposto. Essa discussão pode impulsionar uma necessária intervenção por parte dos que se encontram em estágio, enquanto extensão da Universidade, através dos conceitos e das práticas inovadoras desenvolvidos nas aulas de Estágio ao longo do processo formativo das/os futuras pedagogas/os.

Os relatórios indicam também que os espaços formativos ainda sofrem muita influência dos métodos tradicionais, que desvalorizam a importância das vivências das crianças, tornando-as expectadoras do próprio processo formativo. Nesse contexto, o adulto, contrariando os preceitos da Sociologia da Infância, ainda figura como redentor do conhecimento e direcionador de todas as ações das crianças. Os métodos tradicionais aparecem nos relatórios através das práticas dos adultos explicitadas nas discussões a respeito das três categorias apresentadas acima.

Outro ponto a destacarmos aqui é como os gestores e os profissionais da Educação Infantil entendem a relação do cuidar e educar, principalmente das crianças de até 3 anos, uma vez que precisam estar atentos que, para o processo formativo acontecer, vários fatores se fazem necessários, como o cuidado, o ambiente do contexto formativo, a reflexão, o educar e a afetividade entre os envolvidos.

Podemos concluir, por fim, que os relatos nos mostram que a relação entre adulto e criança depende do olhar que o educador desenvolve sobre o conceito de criança e infância. $\mathrm{O}$ entendimento da criança como sujeito que precisa de mais do que ser cuidado, ser humanizado, ser autor do seu conhecimento, levando em consideração o que ele sabe, é a base para uma relação de respeito, segundo Arendt (2002), sem autoritarismo, mas com autoridade. Reiteramos, portanto, a urgência de que sejam efetivados os direitos da criança na sua inteireza nos contextos educativos de Três Lagoas (MS).

\section{REFERÊNCIAS}

Cadernos Cajuína, v. 6, n. 4, 2021, p. 142-155. 
ANDRÉ, M. O que é um estudo de caso qualitativo em educação? Revista da FAEEBA Educação e Contemporaneidade, Salvador, v. 22, n. 40, p. 95-103, jul./dez. 2013.

ARENDT, H. Entre o passado e o futuro. 5. ed. São Paulo: Ed. Perspectiva, 2002.

ARIÈS, P. História social da criança e da família. Rio de Janeiro: LTC, 1981.

BRASIL. [Constituição (1988)]. Constituição da República Federativa do Brasil de 1988. Brasília, DF: Presidência da República, [2020]. Disponível em: http://www.planalto.gov.br/ccivil_03/constituicao/constituicao.htm. Acesso em: 31 mar. 2021.

BRASIL. Diretrizes Curriculares Nacionais para a Educação Infantil. Brasília: Câmara de Educação Básica do Conselho Nacional de Educação, 1998.

BRASIL. Lei no 9.394, de 20 de dezembro de 1996. Estabelece as Diretrizes e Bases da Educação Nacional. Diário Oficial da União, Brasília, DF, 23 dez.1996.

CHIZZOTTI, A. Pesquisa qualitativa em Ciências Humanas e Sociais. Petrópolis: Vozes, 2006.

KRAMER, S. A política do pré-escolar no Brasil: a arte do disfarce. São Paulo: Cortez, 1995.

KUHLMANN JR., M. Histórias da educação infantil brasileira. Revista Brasileira de Educação, n. 14 , p. 5-18, maio-ago. 2000.

MARCÍLIO, M. L. História social da criança abandonada. São Paulo: Hucitec, 1998.

MENDES, S. L. Tecendo a história das instituições do Brasil infantil. Saberes, Natal, v. 1, n. 11, p. 94-100, fev. 2015. Disponível em: https://periodicos.ufrn.br/saberes/article/download/6685/5206/. Acesso em 03/04/2021.

PASCHOAL, J. D.; MACHADO, M. C. G. A história da educação infantil no Brasil: avanços, retrocessos e desafios dessa modalidade educacional. Revista HISTEDBR On-line, Campinas, v. 9, n. 33, p. 78-95, mar. 2009. Disponível em: $<$ https://periodicos.sbu.unicamp.br/ojs/index.php/histedbr/article/view/8639555 $>$. Acesso em 29/03/2021.

SARMENTO, M. J. A sociologia da infância e a sociedade contemporânea: desafios conceituais e praxeológicos. In: ENS, Romilda Teodora e GARANHANI, Maryelma Camargo. (org.). A sociologia da infância e a formação de professores. Curitiba: Champagnat, 2013.

RICHTER, A. C. Sobre a presença de uma pedagogia do corpo na educação da infância: retratos e vozes, lugares e tempos da corporalidade na rotina de uma creche. Florianópolis, 2005. 169 f. Dissertação (Mestrado em Educação) - Programa de Pós-Graduação em Educação, Universidade Federal de Santa Catarina, Florianópolis, 2005. 